\title{
The private GP and leprosy: a study
}

\author{
M W UPLEKAR* \& R A CASH \\ Takemi Program in International Health, Harvard School of Public \\ Health, 665 Huntington Avenue, Boston, MA 02115, USA
}

Accepted for publication 4 January 1991

\begin{abstract}
Summary In urban and rural areas alike, people in India tend to prefer private medical care to the existing government health services. Nevertheless, the large private health care sector has hitherto been virtually alienated from activities of public health importance including priority disease control programmes. This study of 106 private general practitioners (GPs), practising in low socioeconomic areas of Bombay, shows a gross lack of knowledge and awareness among private doctors about leprosy and also about the National Leprosy Control Programme. The possible reasons are discussed. Effective involvement of GPs in the National Leprosy Control Programme should facilitate both integration and better implementation of leprosy control activities. The study also highlights some areas for future interventions at both primary and secondary health care levels and the need for a strategy, based on larger studies, to train and make private doctors participate in controlling diseases of major public health concern like leprosy.
\end{abstract}

\section{Introduction}

According to WHO, leprosy prevalence is currently estimated at 10-12 million cases in the world. ${ }^{1}$ India has an estimated 4 million cases. ${ }^{2,3}$ The prevalence rate for the state of Maharashtra in Western India is estimated to be 6.7 per thousand. ${ }^{3}$ In the low socioeconomic areas of Bombay city, the prevalence rate of leprosy is about 12 per thousand. ${ }^{4,5}$ Health care in Bombay is organized by a mixture of public and private health providers. It is believed that about $60 \%$ of the population of Bombay city is cared for by private medical practitioners, modern and traditional, and that the remainder are dependent on municipal and government health services. ${ }^{6}$ This is no different from other parts of Maharashtra. In rural and urban areas alike, only $40 \%$ of the people utilize government health services. ${ }^{7}$ However, few attempts have been made so far in India to involve GPs into any of the national disease control programmes.

Leprosy deserves a special place because of the social stigma attached not only to the

* Present address and correspondence: The Foundation for Research in Community Health, 84-A, R G Thadani Marg, Worli, Bombay 400 018, India. 
patients suffering from the disease but also to the health care services and personnel working in the field of leprosy. ${ }^{8}$ The present study examines the knowledge and awareness of leprosy among private doctors - usually the first contact of a patient—practicing in the slums of Bombay. An assessment of their knowledge, attitudes, practices and beliefs about leprosy is expected to help identify the areas of investigation and intervention for their active cooperation and participation in leprosy control.

\section{Materials and methods}

Urban slums in metropolitan cities like Bombay, where about half the population lives in slums, provides a unique situation where both diseases and doctors are in abundance. Table 1 summarizes the major characteristics of the areas providing varying exposures to leprosy control activities to the GPs selected for the study.

\section{SELECTION OF AREAS}

With a view to including practising private doctors, who have had varying exposures to leprosy control activities, three areas in the slums of Bombay were selected for the study, each having different characteristics. Area A has a municipal leprosy clinic, no voluntary agency working in the field of leprosy is operating in this area. GPs practising here have not received any formal training in leprosy. Area B has two peripheral leprosy clinics, both run by a voluntary agency active in the field of leprosy, also no GP in this area has received any formal training in leprosy. Area $\mathrm{C}$ also has two leprosy clinics, one run by the municipality and the other by another voluntary organization, this voluntary organization (Bombay Leprosy Project) had offered an intensive orientation and training programme in leprosy to GPs practising in the area in 1981-1982. The GPs were then followed up for about 18 months by the project staff to encourage them to diagnose and treat leprosy patients in their own clinics and reduce referrals to specialist centres.

\section{SELECTION OF SAMPLES}

One-hundred and six private practising doctors (GPs) were included in the study. From areas $\mathrm{A}$ and $\mathrm{B}$, a list of practising doctors was made and a simple random sample was drawn from all practising GPs irrespective of their age, years of practise and professional qualifications. In area C, 2 doctors who had not participated in the training programme

Table 1. Characteristics of the areas and GPs

\begin{tabular}{lccc}
\hline Area & A & B & C \\
\hline Practising doctors & 148 & 80 & 71 \\
Doctors interviewed & 52 & 29 & 25 \\
Municipal leprosy clinic & One & None & One \\
PVO leprosy (clinics) & None & Two & One \\
Past training in leprosy & No & No & $\begin{array}{c}\text { Yes } \\
\quad \text { in practice) }\end{array}$ \\
\hline
\end{tabular}


Table 2. The questionnaire

1 Do you come across leprosy patients in your clinic?

2 Do you treat leprosy patients in your clinic?

3 What are the classified types of leprosy?

4 When do you suspect leprosy? How do you confirm diagnosis?

5 How do you treat tuberculoid leprosy?

6 How do you treat lepromatous leprosy?

7 When do you stop treatment in the above types of leprosy?

8 Should leprosy patients be referred to specialists? Why?

9 Do you suggest isolation of a leprosy patient on treatment?

10 What causes leprosy? Could you name the causative organism?

11 Should a cured leprosy person be allowed to work in public places?

12 What do you know about the National Leprosy Control Programme?

were not included in the list. A random sample was drawn from the remaining doctors who had undergone training in leprosy then provided by the Bombay Leprosy Project.

\section{DATA COLLECTION AND ANALYSIS}

Doctors were interviewed individually, face-to-face, in their clinics. Responses to an open ended, structured questionnaire (Table 2) were recorded on the spot. Doctors were not obliged to answer any questions they chose not to. The responses were then compiled and analysed.

\section{Results}

Table 3 illustrates classification of replies and performance of doctors in the three areas in response to basic questions on leprosy. The response rate was $100 \%$.

\section{LEPROSY PATIENTS IN PRIVATE CLINICS}

All except 2 of the 106 doctors interviewed had met leprosy patients in their clinics. However only $38 \%$ from area A, $21 \%$ from area B and $20 \%$ from area C were treating them in their own clinics, while the rest preferred to refer them to private or government specialists. The 2 doctors who had never met leprosy patients in their clinics were from area A. They did not answer many of the further questions posted to them.

\section{CLASSIFIED TYPES OF LEPROSY}

For control programmes, WHO has classified leprosy into two major types-'multibacillary' if the slit-skin smears of a case show the presence of acid-fast bacilli and 'paucibacillary' if they do not. ${ }^{2}$ These two broad types include various types for which different classifications exist. The most recent and generally accepted classification includes 5 subtypes - tuberculoid, borderline-tuberculoid, midborderline, borderlinelepromatous and lepromatous. The only doctor who gave a correct answer was from area A. Partially correct replies were recorded by $68 \%$ of doctors from area A, 55\% from area 
Table 3. Performance of GPs in three areas on key questions about leprosy

\begin{tabular}{|c|c|c|c|}
\hline \multirow[b]{2}{*}{ Questions and Answers } & \multicolumn{3}{|c|}{$\begin{array}{c}\text { Performance by area } \\
(\%)\end{array}$} \\
\hline & A & B & $\mathrm{C}$ \\
\hline
\end{tabular}

Q Classified types of leprosy

A Correct: Any answer mentioning two broad types of leprosy (tuberculoid and lepromatous; or paucibacillary and multibacillary; or smear positive and smear negative) with or without a mention of any intermediate types.

Partially correct: A correct mention of any one of the major types or subtypes.

Incorrect: Other than above

No response:

$\begin{array}{rrr}2 & 0 & 0 \\ 68 & 55 & 36 \\ 0 & 0 & 0 \\ 30 & 45 & 64\end{array}$

\section{Q Diagnosis of leprosy}

A Correct: Clinical examination and slit-skin smears for AFB and skin biopsy if necessary.

Partially correct: Mention of any one of the investigative procedures. (skin smears/skin biopsy)

Incorrect: Other than above.

No response:

$\begin{array}{rrr}88 & 76 & 80 \\ 0 & 0 & 0 \\ 2 & 0 & 0 \\ 10 & 24 & 20\end{array}$

\section{Q Treatment of tuberculoid leprosy}

A Correct: (WHO recommendation); Dapsone $100 \mathrm{mg}$ per day and rifampicin $600 \mathrm{mg}$ once a month for 6 months at least. Partially correct: Correct mention of drugs with or without correct dosages or correct duration.

Incorrect: Other than above.

No response:

$\begin{array}{rrr}0 & 0 & 0 \\ 13 & 24 & 8 \\ 23 & 7 & 12 \\ 64 & 69 & 80\end{array}$

\section{Q Treatment of lepromatous leprosy}

A Correct: (WHO recommendation); Dapsone $100 \mathrm{mg}$ per day; rifampicin $600 \mathrm{mg}$ once a month and clofazimine $300 \mathrm{mg}$ once a month followed by $50 \mathrm{mg}$ per day for 2 years at least.

Partially correct: Correct mention of drugs with or without correct dosages and duration.

Incorrect: Other than above

No response:

\section{Q Name of the causative agent of leprosy}

A Correct: Mycobacterium leprae.

Partially correct: Mycobacteria.

Incorrect: Other than above

No response:

$\begin{array}{rrr}0 & 0 & 0 \\ 0 & 0 & 0 \\ 27 & 52 & 28 \\ 73 & 48 & 72\end{array}$

\section{Q Knowledge of National Leprosy Control Programme}

A Correct: A programme run by the central government for control of leprosy. The programme conducts, through existing and special health centres, survey, education, treatment and other services for leprosy patients, free of cost.

Partially correct: Any answer partly suggesting the above.

Incorrect: Other than above.

No response:

$2-7$
$0-1$

$0 \quad 0 \quad 0$

$\begin{array}{lll}40 & 34 & 92\end{array}$

$\begin{array}{lll}58 & 59 & 0\end{array}$


B and $36 \%$ from area C. Thirty per cent of the GPs from area A, 45\% from area B and $64 \%$ from area $C$ chose not to reply.

\section{DIAGNOSIS OF LEPROSY}

Presence of one or more anaesthetic skin patches is diagnostic of leprosy. In lepromatous variety, there may be other skin lesions. Peripheral nerves are involved in most types. The diagnosis and classification is confirmed by slit-skin smears or skin biopsy if necessary, to judge the quantity and to some extent viability of the organisms. Ten per cent of the doctors from area A, 24\% from area B and $20 \%$ from area C did not reply to this question. The replies of $88 \%$ from area $\mathrm{A}, 76 \%$ area $\mathrm{B}$ and $80 \%$ from area $\mathrm{C}$ were almost correct while only one doctor from area A gave an incorrect reply.

Questions 5-7, inquiring about treatment of leprosy were not answered by those doctors who did not treat leprosy patients in their clinics. Those who responded included $38 \%$ from area A, $21 \%$ from area B and $20 \%$ from area C.

\section{TREATMENT OF LEPROSY}

Only 3 drugs are used in the treatment of leprosy and WHO recommendations about drug regimens to be used are unchanged since 1982. Thirteen per cent of GPs from area A, 24\% from area $\mathrm{B}$ and $8 \%$ from area $\mathrm{C}$ were using correct drugs for the treatment of tuberculoid leprosy but not in correct dosages. The rest were employing less or more than adequate drug regimes. None of the doctors followed the recommended regime correctly in all respects with regard to drugs used, dosage and duration. Fifty-three per cent from area A, $44 \%$ from area B and $20 \%$ from area $C$ had never treated a case of lepromatous leprosy. Of those who did, only two, one each from areas $\mathrm{B}$ and $\mathrm{C}$ had used correct drugs but in haphazard dosages.

\section{CESSATION OF TREATMENT}

None of the doctors interviewed had a clear idea of when to stop treatment. A very wide range of responses were noted, from less than 6 months treatment to life-long treatment, without knowledge of the rationale behind it.

\section{REFERRAL OF PATIENTS}

Thirty-eight per cent from area A, $21 \%$ from area B and $20 \%$ from area C felt that patients need to be referred to specialists only if they fail to respond or complications like exacerbations occur during the course of treatment. Twenty per cent from area A, $24 \%$ from area $\mathrm{B}$ and $16 \%$ from area $\mathrm{C}$ were concerned that by treating leprosy patients in the clinics they may adversely affect their practice, while the remaining were convinced that leprosy patients always need specialist care.

\section{ISOLATION OF PATIENTS}

An expected reply was obtained from only two doctors, one each from areas B and C, who were emphatic in saying that there is no need for isolation if a patient is on regular 
treatment. Seventy-eight per cent of doctors from area A, 76\% from area B and $24 \%$ from area $\mathrm{C}$ favoured isolation of patients if possible while the remaining felt that isolation should be compulsory.

\section{CAUSE OF LEPROSY}

When asked what causes leprosy, $73 \%$ of doctors from area A, $48 \%$ from area B and $72 \%$ from area $\mathrm{C}$ chose not to reply. The remaining mentioned various causes such as germs, infection, and close contact with a leprosy patient. One doctor from area A still believed that leprosy is hereditary. When asked to name the causative organism of leprosy, none of the doctors from any of the three areas could do so.

\section{REHABILITATION}

In reply to the question, whether a person cured from leprosy should be allowed to work in public places, $36 \%$ of doctors from area A, 59\% from area B and $88 \%$ from area C answered in the affirmative; $40 \%$ from area $\mathrm{A}$ and $7 \%$ from area $\mathrm{B}$ replied in the negative while $34 \%$ from area $\mathrm{A}, 34 \%$ from area $\mathrm{B}$ and $12 \%$ from area $\mathrm{C}$ refused to reply.

\section{AWARENESS ABOUT NATIONAL CONTROL PROGRAMME}

Most doctors were unaware of any activity being carried out under the banner of such a programme. All doctors from areas B and C and a majority (80\%) from area A knew of the many groups (non-governmental organizations) engaged in antileprosy work. Most doctors felt that nothing special was being done for leprosy. Free treatment is given in public hospitals for leprosy as it is for any other disease, there are a couple of leprosy hospitals just as there are hospitals for tuberculosis or other infectious diseases.

\section{Discussion}

It is reasonable to expect a GP practising in an area endemic for leprosy with a prevalence rate of over 10 per thousand to know basic facts about the disease. Despite the fact that most GPs did come across leprosy patients in their clinics, their response to simple questions on leprosy exhibit a gross lack of knowledge and awareness about leprosy. Ramanathan \& Ramu, in their study of the attitudes of doctors engaged in antileprosy work under the National Leprosy Eradication Programme found that $33 \%$ had inadequate knowledge about the disease. ${ }^{9}$ They observed that this could be a result of disinterest among the 'leprosy doctors' caused by fears of being socially stigmatized and facing poor job prospects. According to Duggal et al. leprosy is considered a 'punishment posting' and leprosy workers, especially physicians are not only most disinterested in their work but also exhibit stigma towards the disease. ${ }^{10}$ These and other studies maintain that the status accorded to a leprosy programme and as a consequence to those who work in it is very low. ${ }^{8,11}$ The observations on doctors working full-time in leprosy highlights the concern of doctors about their image with regard to society and work prospects. Would these observations also apply to doctors engaged in private medical practice?

No direct questions were posed to GPs about 'stigma', but only a minority of doctors (about $20 \%$ ) from all three areas felt worried about their practice being affected adversely 

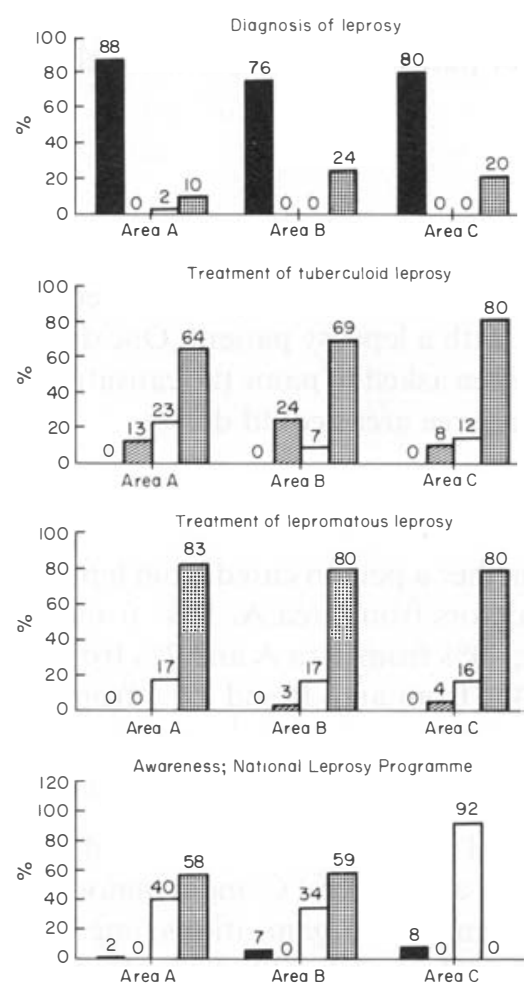

Figure 1. Performance of doctors. See Table 2 for details. Responses of doctors: $\mathbf{n}$, correct; , partially correct; $\square$, incorrect; 图, no response.

by treating leprosy patients in their clinics. This is understandable, since for doctors who would be willing to treat them, leprosy patients would form only a small part of their general medical practice.

Although the private doctors practising in area $\mathrm{C}$ had received formal training in leprosy offered by a nongovernmental organization many years before, the performance of doctors in all three areas appeared consistent. Figure 1 illustrates the comparative performance of private doctors in the three areas on key questions about leprosy.

The voluntary agency that conducted short-term training and provided the services of a leprosy technician to the GPs had found, during their 18 months follow-up, that there was a significant increase in the number of patients being properly treated by GPs in their own clinics. ${ }^{6}$ It seems that the eff ect of training had diminished and disappeared over the years emphasizing the need for the regular follow-up of training activities and continuing education. Also, since the clinic run by the voluntary agency in the area continued to function after conclusion of the training activity, GPs pref erred to ref er their cases to the clinic rather than treat them in their own clinics. The effect of training was seen only in the responses obtained for the questions regarding isolation of leprosy cases and rehabilitation of cured leprosy patients. Unlike doctors in areas A and B, a large majority of doctors in area $\mathrm{C}$ thought it safe not to isolate leprosy cases while on treatment and to let cured leprosy patients work in public places. 
The choice given to responders to be able not to answer a question was done essentially to prevent embarrassment to the doctor being interviewed. While these are maintained as nonresponses, it may not be unfair to conclude retrospectively, taking into consideration the overall findings of the study, that the most probable reason for the nonresponse was a lack of knowledge.

Clearly, far too many doctors from all three areas performed poorly. In fact, health planners already expect little if anything from private doctors that might benefit public health problems like leprosy. Early detection, prompt reporting, optimal treatment, sound advice to the patient about the importance of regular treatment and to his contacts about the infectiousness of the disease, and facilitating rehabilitation constitute services private doctors should provide routinely.

Doctors in all the three areas performed best when asked about diagnosis of leprosy. However, they did not do as well when it came to treatment (Figure 1). One of the reasons for this, besides of course lack of training, could result from a proliferation of, and confusion about, contradictory drug regimes advocated by private medical consultants, educational institutions and voluntary agencies. Until recently the recommendations for treatment by the Indian Association of Leprologists were different from those by WHO. Even today, senior specialists continue to prescribe regimes which vary from one patient to another. The resultant confusion might mystify simple guidelines about treatment of leprosy deterring GPs from treating patients. This also highlights the role of specialists at secondary and tertiary care levels in public health. While their freedom and competence of treating a case may not be questioned, in dealing with diseases of public health importance like tuberculosis or leprosy, the senior specialists should try and stick to one rule so that those at the periphery could follow their actions. If they must deviate, they should clarify the rationale behind their actions to the referring GPs, junior doctors or students, their patients and others who need to know. Better communication would prevent confusion about the choice of drugs, duration of treatment, need for isolation and opportunities for rehabilitation.

It is both surprising and sad that the priority national control programmes exert so little influence on private doctors. It is unlikely that doctors would intentionally prescribe incorrectly if they knew what they should prescribe. When the pharmaceutical industry can successfully promote any number of irrational and non-essential products, why cannot the government promote its own programmes to GPs, who have to depend on the pharmaceutical industry to update their knowledge? Unfortunately no national disease control programme has, as one of its integral components, the continuing education of medical personnel at all levels.

The nongovernment organizations may also play a vital role, with the help of their motivated work force, in carrying control programmes to private clinics. Like the organization in this study, it could be worthwhile for similar organizations to facilitate integration of leprosy into general health services by encouraging private doctors to treat leprosy patients in their clinics. Doctors may be willing to participate if facilities like laboratory services for skin-smear examinations and the right type of drugs are provided for the convenience of their patients. The general notion that private doctors are interested in nothing but profits derived from their practice and are incapable of providing any inputs for implementation of disease control activities is certainly not based on the results of any kind of attempts or experiments to involve them. 


\section{Conclusions}

The private doctors serving the urban poor in the slums of Bombay, with or without exposure to the existing leprosy control activities, have a grossly inadequate knowledge of a major, highly prevalent disease like leprosy although many people first seek their services. This could be due to the lack of adequate basic and continuing education of private doctors on major diseases of public health importance. Stigma attached to leprosy and general apathy among private doctors about national disease control programmes could be other contributory factors.

Most private doctors practising in urban slums identify leprosy patients in their clinics, and they know how to diagnose leprosy. Many however prefer to refer these cases to specialists for treatment. Those who treat them are confused about which drugs to prescribe and for how long. This could be a result of inconsistencies in recommendations and practices observed by specialists in the leprosy control programmes, educational institutions and those in private practice. Those responsible for giving out leprosy information could improve the implementation of leprosy control by GPs, e.g. by providing laboratory services, giving adequate information about the National Control Programme and updating the GPs knowledge by frequent communications.

Further research on the role of private doctors in public health considering deficiencies in basic medical education and continuing medical education would make it possible to remedy the problems our study has identified. The communicable diseases for which no truly effective vaccines exist, adequate treatment and cure of a case constitute the most important measures of control and these are the primary functions of a practising doctor. Appropriate incentives and sanctions may be provided by the government to encourage private doctors to actively participate in implementation of major disease control programmes.

\section{Acknowledgments}

This paper is an outcome of a Research Fellowship awarded to the author in the Takemi Program in International Health at the Harvard School of Public Health. The author deeply appreciates the valuable comments and suggestions of Drs Mitchell Weiss, Michael Reich, Lincoln Chen and other participants of the Takemi Research Seminar. The support of Dr N H Antia, Director and Mr Madhu Rokle, Research Investigator of the Foundation of Research in Community Health, Bombay, in designing and conducting the study is gratefully acknowledged.

\section{References}

1 WHO. Expert Committee on Leprosy. Technical Report Series No. 768. WHO: Geneva, 1988.

2 WHO. A Guide to Leprosy Control. 2nd Edition. WHO: Geneva, 1988.

${ }^{3}$ Health Information of India. Director General of Health Services, New Delhi, India, 1987.

${ }^{4}$ Ganapati R, Revankar CR, Dongre VV. Prevalence of leprosy in Bombay including a leprosy colony. Ind J Lepr, 1985; 57: 383-8.

5 Marshall JT, Amar DS, Ramesh HC. Prevalence of leprosy among slum-dwellers. Lepr India, 1981; 53: 70 82. 
${ }^{6}$ Revankar CR, Jha SS, Dongre VV, Deshpande SS, Ganapati R. Integration of Leprosy into general health services in an urban area-a feasibility study. Le pr Rev, 1982; 53: 297-305.

7 Jesani A, Gupte M, Duggal R. NGOs in Rural Health Care. Vol. 1 (Overview). Published by the Foundation for Research in Community Health, Worli, Bombay, 1986.

8 Antia NH. Leprosy control by a people's program: a new concept in technology transfer. Int J Health Serv, 1987; 17(2): 327-31.

9 Ramanathan U, Ramu G. Attitude of doctors to working in leprosy. Ind J Lepr, 1986; 54(4): 695-9.

10 Duggal R, Jesani A, Gupte M. Social Aspects of leprosy: Findings from Rural Maharashtra. A Damien Foundation Study conducted and published by The Foundation for Research in Community Health, Bombay, India, 1988.

11 Rao KV. Study of Leprosy Control Programs in a Rural Population [PhD thesis]. J N University, Delhi, $1982,73 \mathrm{pp}$.

Lepr Rev (1991) 62, 410-19

\section{Le médecin généraliste privé et la lèpre: une étude}

\section{W UPLEKAR ET R A CASH}

Résumé Dans des zones rurales aussi qu'urbaines, les gens de l'Inde préfèrent normalement avoir des soins médicaux privés au lieu de se soummetre aux services d'hygiène de l'etat déjà existents. Néanmoins, le secteur privé des soins médicaux, bien qu'il est important, a été jusqu'ici presqu'aliéné de toute activité d'importance pour la salubrité publique, y compris les programmes prioritaires pour le contrôle des maladies. Cette étude de 106 médecins généralistes privés exerçant dans des zones de bas niveau socio-économique à Bombay, découvre entre ces médecins une manque crasse de connaisance et de sensitivité sur la lèpre et aussi sur le Programme National pour le Contrôle de la Lèpre. On discute les possibles raisons à la base de cette situation. Une participation éffective des médecins généralistes devrait aider l'intégration et aussi la meilleure mise en exécution des activités pour le contrôle de la lèpre. L'étude souligne aussi quelques secteurs pour intervention à l'a venir au niveau primaire autant que sécondaire de soins médicaux et le besoin d'a voir une stratégie, basée sur des études à plus grande échelle, pour former les médecins privés et leur obliger à participer dans le contrôle des maladies de grande importance pour la salubrité publique comme, par exemple, la lèpre.

\section{El médico general privado y la lepra: un estudio}

\section{W UPLEKAR Y R A CASH}

Resumen En zonas rurales tanto como urbanas, la gente en la India suele preferir recibir asistencia médica privada en vez de someterse a los servicios sanitarios del estado ya establecidos. Aún así, hasta ahora el importante sector privado de asistencia sanitaria ha permanecido casi completamente al margen de las actividades relativas a la salud pública inclusive los programas prioritarios para el control de enfermedades. Este estudio de 106 médicos generales privados, ejerciendo en zonas de bajo nivel socio-económico de Bombay, muestra una gravecarencia de conocimientos y de entendimiento entre los médicos privados acerca de la lepra y también acerca del Programa Nacional para el Control de la Lepra. Se discuten las posibles razones de esta situación. La participación eficaz de los médicos generales en el Programa Nacional para el Control de la Lepra debiera de facilitar tanto la integración como una puesta en práctica más eficaz de las actividades para el control de la lepra. También subraya el estudio algunos sectores para futuras intervenciones a niveles primarios y secundarios de asistencia sanitaria y la necesidad de desarrollar una estratégia, a base de estudios más amplios, para que la formación de los médicos privados les imponga a participar en el control de enfermedades de importancia máxima para la salud pública como, por ejemplo, le lepra. 